\title{
Infant Care takes a Hammering
}

by our Washington Correspondent

To the embarrassment of some and the concern of many, the United States, for all its material wealth, has a high rate of infant mortality. The rate is, in fact, higher than in some 13 other countries. That statistic has, not surprisingly, been widely used as a stick with which to beat the health care system in the United States, particularly for failing to provide adequate services to the poor and to minority groups. Last week, such charges were placed on a much firmer footing with the publication of a meticu. lous study of birth records in New York City (Infant Death: An Analysis by Maternal Risk and Health Care, available from the National Academy of Sciences, 2101 Constitution Ave., Washington DC 20418. $\$ 6.00$ paper, $\$ 8.00$ cloth).

Carried out under the auspices of the Institute of Medicine, part of the National Academy of Sciences, the study involved examining the records of all the births which took place in New York in 1968-more than 140,000 in all. It was found that 21.9 infants in every 1,000 born that year died before they were 12 months old. Their chances of survival were found to be strongly correlated with the quality of health care that their mothers received during preg. nancy, and the group that carried out the study found that there is a "gross misallocation of services by ethnic group". If all the women in New York who gave birth in 1968 had received adequate prenatal care, infant mortality could have been cut by one third, the study suggests.

A central feature of the study was an attempt to determine, on the basis of social and medical factors, which mothers run a risk of having infants with lower chances of survival, and then to see whether the risks are ameliorated by proper health care during pregnancy. Social risk was determined on the basis of such factors as the mother's education, age, marital status and number of children, while medical risk took into account such factors as blood pressure, pelvic size and so on. All such data were contained in the 1968 New York birth records.

The correlations between high risk groups and infant mortality are striking. Those infants whose mothers were assigned to both the social and medical risk groups had a mortality rate of 42 per thousand in the first year of their lives; those whose mothers were assigned to either the medical or the social risk group had mortality rates of 27.7 per 1,000 and 24.9 per 1,000 respectively, and those whose mothers came from the no-risk group had a mortality rate as low as 12.1 per thousand.

As for the effect of health care, the study rated the care according to the number of visits the mother made to her doctor during pregnancy, the time of her first visit and the kind of hospital service during delivery. Again, the correlation is striking with, on average, a two-fold difference in mortality rates from 13.3 per 1,000 infants of mothers deemed to have had adequate health care, to 35.6 per 1,000 infants whose mothers received inadequate care.

But those figures tell only half the story, for there is a very marked racial imbalance not only among the risk groups, but also according to the quality of health care received.

Some 60 per cent of the white, native born mothers were placed in the no-risk group, compared with only 25 per cent of the black mothers. Moreover, about three times as many black women as white were assigned to the social risk group. As for quality of health care, some 43.3 per cent of the white, nativeborn mothers received adequate care

\section{TECHNOLOGY ASSESSMENT \\ Sethack for OTA}

by our Washington Correspondent

THE Office of Technology Assessment (OTA), Congress's new advisory and investigative body for technological matters, has received yet another setback. For the past nine months, the OTA has existed in name only and, thanks to a little-noticed provision that came as part of Congress's historic ban on the bombing of Cambodia, it is going to remain that way for some time. The root of the problem is the tortuous appropriations process.

In short, although the OTA was established by a bill passed in October last year, it cannot get under way, no director can be appointed and no staff taken on until it gets some money. And that requires a separate act of Congress. Supporters of the OTA, led by Senator Edward M. Kennedy, who has been elected chairman of the office's 12member policy board, decided that the quickest way to get funds would be to tack an amendment to the Supplemental Appropriations Bill when it came up for during pregnancy, while only 4.6 per cent of black, native-born women were placed in that category.

An important aspect of the study is that it is easy to identify those women in the high risk groups on the basis of a few simple questions asked during their first visit to the doctor after they become pregnant The study thus suggests that the type of health care should be based on the risk categories, and recommends that the American College of Obstetricians and Gynaecologists should draw up appropriate guidelines for physicians.

But the problem is that health care seems to be so grossly misallocated at present that it will require a radical change in the whole health care system to rectify. According to the study, some 70 per cent of the women who received inadequate health care were also deemed to be at either social or medical risk or both. Even worse, among the 22,000 black and Puerto Rican mothers in the social risk group, less than 2 per cent received adequate health care.

Small wonder, therefore, that $\mathrm{Dr}$ Robert Coles of Harvard University said in a preface to the report that "we do things wrong, we are indifferent to the needs of others-and here, right here is the proof."

a vote in the Senate in May. (The Supplemental Appropriations Bill provided additional funds for a sheaf of government agencies for the 1973 fiscal year.) But, unfortunately for the OTA, the Supplemental Appropriations Bill was turned into a controversial affair when an amendment cutting off funds for hostilities in Indochina was also attached to it. The version passed by the House of Representatives contained a much weaker antiwar provision and the whole issue got bottled up in a conference committee for weeks.

When the bill finally emerged from conference at the end of June, the funding for OTA had been dropped, reportedly because with only a few days of the fiscal year left to run, the house conferees argued that it was not worth providing money for a new agency. The money would, however, have allowed a director and staff to have been appointed, and some studies to be initiated. The upshot is that the OTA must wait until the appropriations for the legislative branch are passed by Congress, and that is unlikely to happen until the end of September at the very earliest. 